\title{
Reliable and Sophisticated Techniques to Evaluate LDPE Degraded Compounds by Streptomyces werraensis SDJM
}

\author{
N. Deepika and R. Jaya Madhuri $\dagger$ \\ Department of Applied Microbiology, Sri Padmavati Mahila Visvavidyalayam, Tirupati-517502 India \\ $\dagger$ Corresponding author: R. Jaya Madhuri
}

Nat. Env. \& Poll. Tech.

Website: www.neptjournal.com

Received: $17-07-2020$

Revised: $17-11-2020$

Accepted: 09-01-2021

Key Words:

LDPE

LCMS technique

GCMS-SPME technique

Streptomyces werraensis SDJM strain

\begin{abstract}
The modern world in the present era made life miserable due to extensive usage of plastic. Low-density polyethylene (LDPE) is widely consumed in every part of the world starting from baby products to garbage bags. Humans and animals are affected due to the usage and disposal of LDPE in the environment. To safeguard the environment from deleterious effects, biodegradation of LDPE was studied by isolating a potent Streptomyces werraensis SDJM strain from garbage soil. The degradation assessment was performed to identify the LDPE degraded compounds such as octane, decane, tetracosane, hexacosane, dotriacontene, tetratiacontene, tridecone, tetracontane, and pentacosane, using a sophisticated technique - liquid chromatography-mass spectroscopy (LCMS). The end product of LDPE biodegradation, carbon dioxide was measured by the GCMS-SPME technique. Field trials in garbage soil for a period of three months reveal $71.26 \%$ weight loss compared to laboratory test results where the weight loss was $60.05 \%$. The morphological changes and structural changes of the polymer in fields were assessed by SEM analysis and FTIR analysis after one month of incubation. The test results in field trials were promising and convincing to overcome the LDPE pollution in presence of S.werraensis SDJM strain.
\end{abstract}

\section{INTRODUCTION}

Low-density polyethylene is a synthetic polymer that plays a vital role in every facet of human life, primarily for packaging food (milk, cereals, pulses, and vegetables), computer components, dispensing bottles, laboratory equipment, garbage bags, etc. Amongst synthetic plastics, one of the most problematic plastics in this regard is polyethylene (PE). Polyethylene or PE is the most common plastic and about 80 million tons of polyethylene is produced worldwide (Piringer $\&$ Baner 2008). LDPE, a polyolefin is produced from olefin (alkene) monomers because olefins contain a reactive double bond. LDPE was first introduced through radical polymerization under high pressure by Imperial Chemical Industries (ICI) in 1933 (Dennis 2010).

Disposal of LDPE through landfills and incineration creates huge environmental pollution (Einas \& Hago 2014, Ingavale \& Raut 2018). Polyethylene waste disposed into oceans disperse all over the water due to buoyancy and is considered as hazardous waste killing aquatic habitat. Incineration of polyethylene waste such as trash bags, grain storage bags, and shopping bags under an open atmosphere at low to high temperatures release toxic fumes such as methane and carbon monoxides that pollute the environment and cause significant health hazards. Some of the significant VOCs released at the time of incineration are polycyclic aromatic hydrocarbons (PAHs), polychlorinated dibenzofurans
(PCDFs, and dioxins which are major carcinogenic hazards to humans (Environment Pollution Board 433 2012).

Physical and chemical methods of degradation techniques are employed to safeguard our ecosystem from toxic carcinogens but none of the methods are really effective to overcome pollution. Low-density polyethylene degradation is enhanced by exposing the polymer to abiotic conditions using UV, chemicals, and high temperature before subjecting to biotic degradation (Gajendiran et al. 2016). Among all the methods of degradation, biodegradation is one of the projecting ways in recent research to reduce environmental pollution and health hazards. The biodegradation of low-density polyethylene can be carried out under aerobic environment and anaerobic environment. Aerobic microbes in the presence of oxygen form thick biomass around the polymer and degrade slowly by releasing carbon dioxide and water as end products whereas, under anoxic conditions, anaerobes release carbon dioxide, methane, hydrogen sulfide, and water (Muthukumar \& Veerappapillai 2015).

There are various analytical techniques to determine the biodegradation of low-density polyethylene. These techniques were used to identify structural changes of the polymer which include physical or morphological changes, chemical changes, and further confirmation through analysis of degraded products. The physical and morphological changes of the low-density polyethylene can be determined visually 
through biofilm formation but further confirmation can be done based on a scanning electron microscope (SEM). SEM technique undoubtedly identifies the changes on the surface of any material as it reveals the details of abrasions and incisions created by the microorganism (Shalini \& Sasikumar 2015).

The chemical changes of the polymer or chemical properties are determined based on the formation or disappearance of functional groups. Functional groups of the polymers were analyzed by Fourier transform infrared spectroscopy (FTIR). The polymer was oxidized through the $\beta$-oxidation process forming carbon dioxide and water as end products (Nupur et al. 2017). The degradation products of lowdensity polyethylene can be determined either by using gas chromatography-mass spectroscopy (GCMS) or liquid chromatography-mass spectroscopy (LCMS) techniques. Polyethylene samples treated with microorganisms were tested by performing GCMS analysis and the spectra reveal that the linear polymer chain was broken into different compounds confirming that microbes play a key role in the degradation of polyethylene.

Soil burial methods or field trails were employed by using a potent microbial strain to reduce pollution. Weight loss, SEM analysis, and thermogravimetric analysis were performed to identify the changes of the PE, true graft of PE-g starch, and the composite of PE-g starch samples through soil burial method using garden soil (Neena \& Inderjeet 2013). The field trials were compared with laboratory conditions using synthetic media through weight loss analysis and it was observed that the soil burial method with compost is more efficient in degrading polyethylene. This confirms that microorganisms in soil play a predominant role to degrade low-density polyethylene (Okoh \& Atuanya 2014).

This study aims to investigate the role of microorganisms from garbage soil to degrade low-density polyethylene under both laboratory and field conditions.

\section{MATERIALS AND METHODS}

1. Low-density polyethylene powder (LDPE) from Sigma Aldrich Chemical Co (Product of USA) was used for degradation studies. LDPE size is $53-75 \mu \mathrm{m}$ and its density was $0.94 \mathrm{~g} \cdot \mathrm{ml}^{-1}$ at $25^{\circ} \mathrm{C}$.

2. Low-density polyethylene film from Pack Worth Polymers (Hyderabad, India) was used for degradation studies

3. Mineral salts medium (MSM g. $\mathrm{L}^{-1}$ ): $\mathrm{KH}_{2} \mathrm{PO}_{4}, 0.2$; $\mathrm{K}_{2} \mathrm{HPO}_{4} 1.6 ;\left(\mathrm{NH}_{4}\right)_{2} \mathrm{SO}_{4}, 1.0 ; \mathrm{MgSO}_{4} .7 \mathrm{H}_{2} \mathrm{O}, 0.2$; $\mathrm{CaCl}_{2} .2 \mathrm{H}_{2} \mathrm{O}, 0.02 ; \mathrm{FeSO}_{4} .7 \mathrm{H}_{2} \mathrm{O}, 0.01 ; \mathrm{NaCl}, 0.1 ; \mathrm{pH}$, $7.2 \pm 0.2$

\section{LCMS (Liquid Chromatography-Mass Spectroscopy) Analysis to Identify the LDPE Degrading Compounds}

Mineral salt broth with LDPE at a concentration of $1 \% \mathrm{w} / \mathrm{v}$ was prepared and inoculated with Streptomyces werraensis SDJM. Control was maintained without organism to check the parent polymer peak. Liquid phase mass spectroscopy was performed to identify the degraded products of low-density polyethylene after one month of incubation along with a control sample. Sample and control were injected into triple quadrupole LCMS sample port.

LCMS was performed using a thermo scientific instrument with LC-ultimate 3000 which was coupled with TSQ-Endure MS with a trace finder data system. The fragmented ions were detected with an electron multiplier detector to develop a chromatogram. The chromatogram obtained was compared with the NIST library to identify the degraded products of low-density polyethylene (Samuel et al. 2009).

\section{GCMS Analysis (Gas Chromatography-Mass Spectroscopy) by SPME Method (Solid Phase Micro Extraction) for Identification of LDPE Degraded Products}

Gas chromatography-mass spectroscopy-solid phase microextraction technique was used to extract the degraded products of low-density polyethylene after one month of incubation with $S$. werraensis SDJM. The fiber was exposed to the medium for $15 \mathrm{~min}$ and retracted slowly into the protective sheet. Then it was inserted into the injector to desorb and GCMS was started simultaneously.

Gas chromatography Mass spectroscopy (GCMS) was performed using Agilent instruments. In this instrument, GC-7890A was coupled with 5975C-MS with a chemstation data system. The chromatogram of the degraded products was compared with NIST 2014 spectra library.

\section{Field Tests}

Field tests were performed to determine the capability of isolated strain S.werraensis SDJM to degrade low-density polyethylene in garbage soil. LDPE bags' initial weight was noted and buried in garbage soil at a depth of $5-30 \mathrm{~cm}$ and $10 \%$ S.werraensis SDJM inoculum was incorporated along with $1000 \mathrm{~mL}$ of mineral salt broth for a period of three months. A control sample was buried without organisms at a different location for comparative studies. After one month of incubation, both control and inoculated LDPE samples were washed with distilled water and air-dried, and weight was recorded. SEM analysis was performed for both control and sample to observe the morphological changes, and structural changes of the polymer were determined 
by FTIR analysis. The weight loss data is recorded for three months and correlated with laboratory experiments (Kathiresan 2003).

\section{RESULTS AND DISCUSSION}

The end products of degradation of low-density polyethylene by S.werraensis SDJM were assessed by liquid chromatography mass spectroscopy. The degraded products were determined by LCMS analysis through the fragmentation pattern and $\mathrm{m} / \mathrm{z}$ values. These unknown compounds formed were evaluated comparing with known compounds through the national institute standard and technology (NIST).

Low-density polyethylene is a linear polymer made up of monomers. The LCMS data reveals that the polymer parent peak was formed at 17.69 RT with 1064 molecular weight. In the treated sample, parent polymer was degraded into small linear aliphatic compounds such as octane, decane, tetracosane, hexacosane, dotriacontene, tetratiacontene, tridecone, tetracontane, and pentacosane. The LCMS spectra and molecular weight of the unknown compounds are represented in Table 1. This data reveals that the S.werraensis SDJM breaks the polymer and forms aliphatic straight chains of alkenes and alkanes (Figs. $1 \& 2$ ).

\section{GCMS Analysis of LDPE}

GCMS analysis was performed through solid-phase mi-

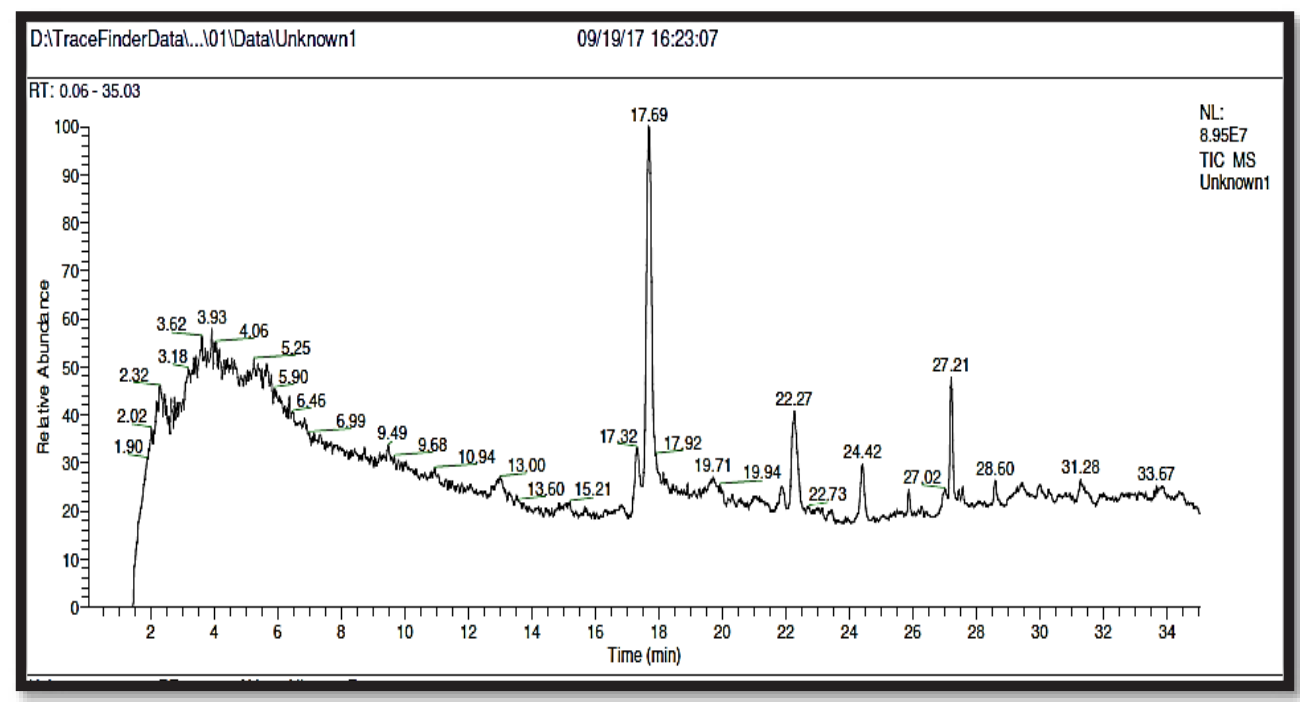

Fig. 1: Mass spectrum of LDPE control.

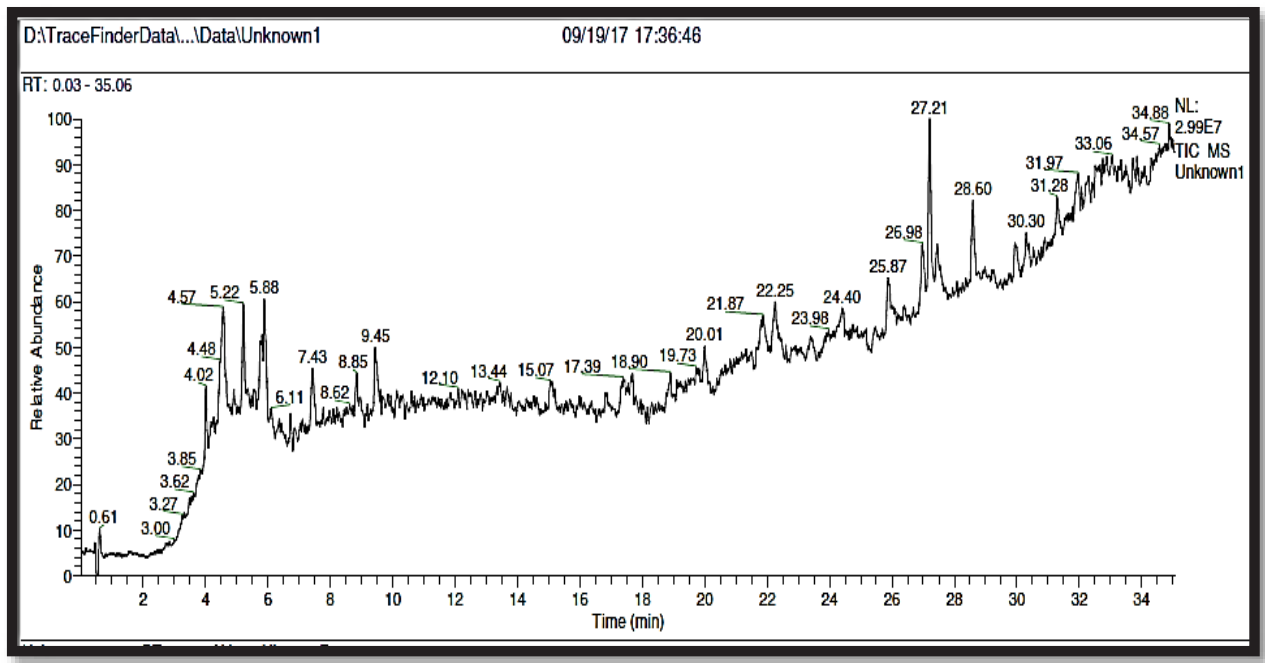

Fig. 2: Mass spectrum of LDPE sample with S.werraensis SDJM. 
croextraction method using GC-7890A and 5975C-MS to identify the volatile compounds of the degraded low-density polyethylene after a period of one month along with control. The SPME fiber was inserted into the sample and kept for $15 \mathrm{~min}$ to adsorb the degraded compounds. Then the fiber was removed and inserted into the sample inlet of GCMS to desorb and analyzed the compounds.
The compound detected was identified as carbon dioxide through the NIST library as the peak formation was identified at $3.365 \mathrm{~min}$. In control, peaks were absent indicating the absence of organism and degradation (Figs. $3 \& 4$ ).

Field Tests for Assessment of LDPE Degradation in Garbage Soil Using Streptomyces werraensis SDJM

Table 1: Degradation products of LDPE.

\begin{tabular}{|c|c|c|c|c|}
\hline S.NO & Retention time(min) & Molecular weight & $\begin{array}{l}\text { IUPAC name of the } \\
\text { compound }\end{array}$ & Structure \\
\hline 1 & 4.02 & 114.232 & Octane $\left(\mathrm{C}_{8} \mathrm{H}_{18}\right)$ & \\
\hline 2 & 4.02 & 142.29 & Decane $\left(\mathrm{C}_{10} \mathrm{H}_{22}\right)$ - & \\
\hline 3 & 4.48 & 338.65 & Tetracosane $\left(\mathrm{C}_{24} \mathrm{H}_{50}\right)$ & \\
\hline 4 & 4.57 & 366.718 & Hexacosane $\left(\mathrm{C}_{26} \mathrm{H}_{54}\right)-$ & \\
\hline 5 & 5.22 & 448.864 & Dotriacontene $\left(\mathrm{C}_{33} \mathrm{H}_{64}\right)$ & \\
\hline 6 & 5.22 & 478.934 & Tetratiacontene $\left(\mathrm{C}_{34} \mathrm{H}_{70}\right)$ & \\
\hline 7 & 5.88 & 184.4 & Tridecone $\left(\mathrm{C}_{13} \mathrm{H}_{28}\right)$ & \\
\hline 8 & 5.88 & 563.096 & Tetracontane $\left(\mathrm{C}_{40} \mathrm{H}_{82}\right)--$ & \\
\hline 9 & 7.43 & 338.65 & Tetracosane $\left(\mathrm{C}_{24} \mathrm{H}_{50}\right)$ & \\
\hline 10 & 7.43 & 352.69 & Pentacosane $\left(\mathrm{C}_{25} \mathrm{H}_{52}\right)$ & \\
\hline
\end{tabular}

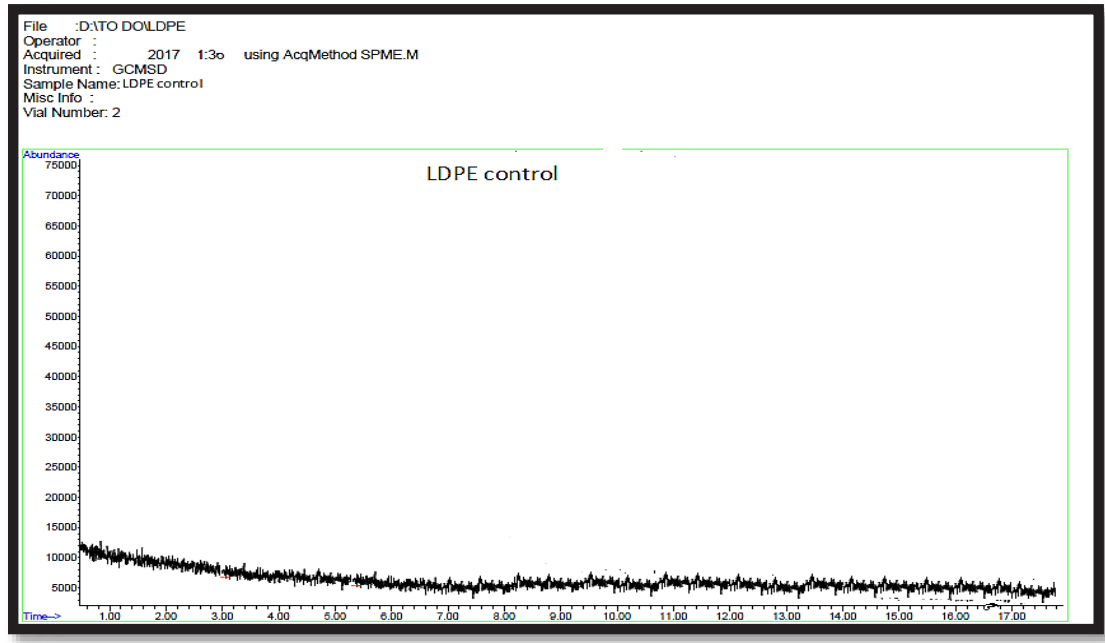

Fig. 3: Mass spectra of control. 


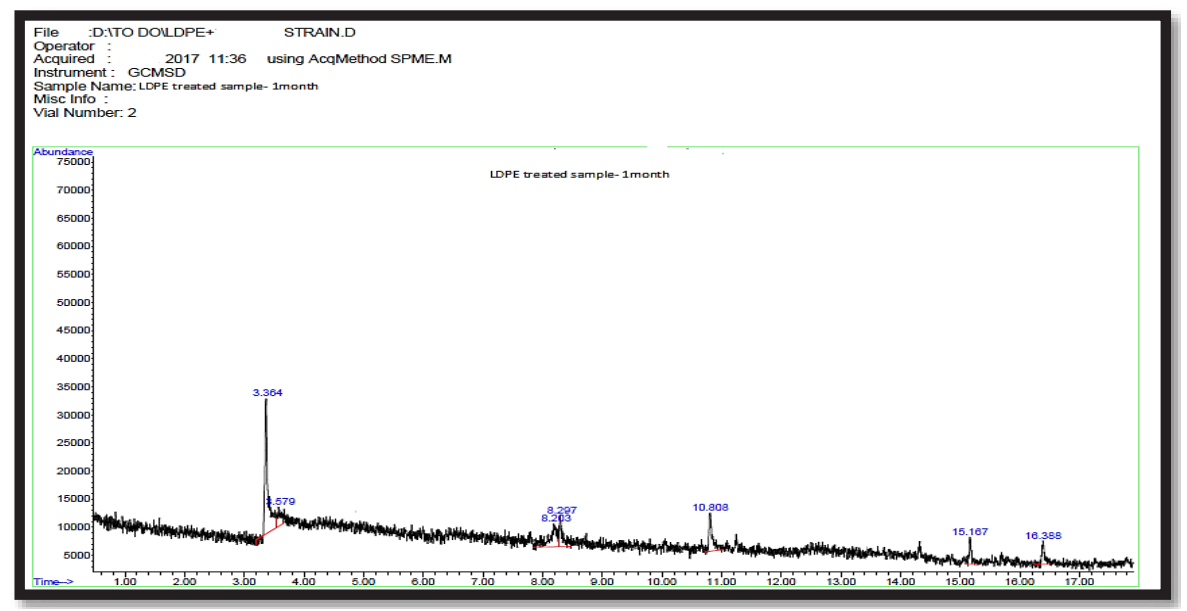

Fig. 4: Mass spectra of the sample.

Field tests were performed to check the efficiency of LDPE degradation using S.werraensis SDJM in garbage soil. The results were correlated with control by burying LDPE at a different location without organism for a period of one month. The changes in the polymer were determined by weight loss, morphological changes by SEM analysis, and structural changes by performing FTIR analysis.

\section{Weight Loss of LDPE}

The initial weight of the LDPE film was measured and buried in garbage soil. After one month, biofilm formation with crack and pits was observed on the surface of LDPE in both control and sample. Yellowing of the film was more in the sample compared to the control sample (Fig. 5). It has been observed the weight loss of the sample buried with S.werraensis SDJM is $60.01 \%$ and the weight loss of the control is $13.97 \%$ in one month (Fig. 6). The weight loss results of field trials were compared with laboratory weight loss results for a period of three months and it was observed that S.werraensis SDJM reduces more weight of the polymer in garbage soil up to $71.26 \%$ by associating with other microbes under natural conditions compared to laboratory conditions i.e $60.05 \%$ (Fig. 7).

\section{Scanning Electron Microscopy (Sem) Analysis for Buried LDPE}

Morphological changes on the surface of both control and sample were analyzed using SEM analysis. Biofilm formation, cracks, pits, and abrasions were observed in both control and sample but more cracks were identified in the sample compared to control (Fig. 8).

\section{FTIR Analysis of Buried LDPE Samples}

FTIR analysis was performed for both LDPE control and sample buried in garbage soil for a period of one month and it was observed that both exhibit structural change due to shift in absorbance and formation of new functional groups.

FTIR spectrum of control LDPE was buried without organism degradation due to soil inhabitants and form peaks at

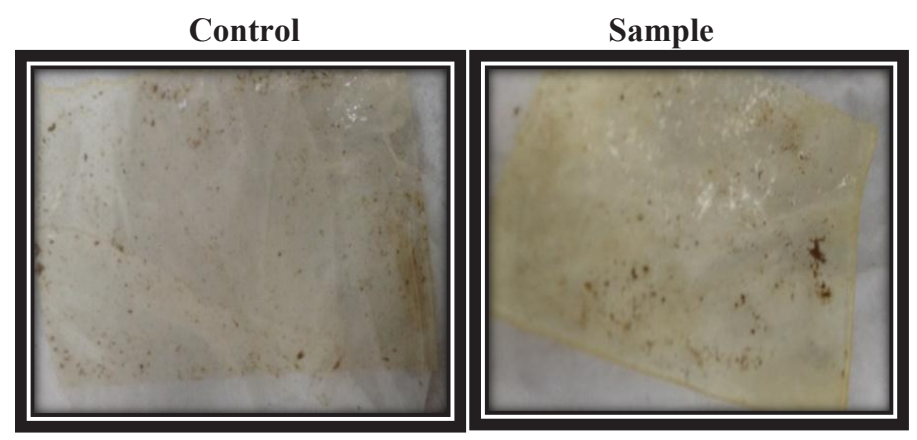

Fig. 5: Biofilm formation on LDPE in field trials. 


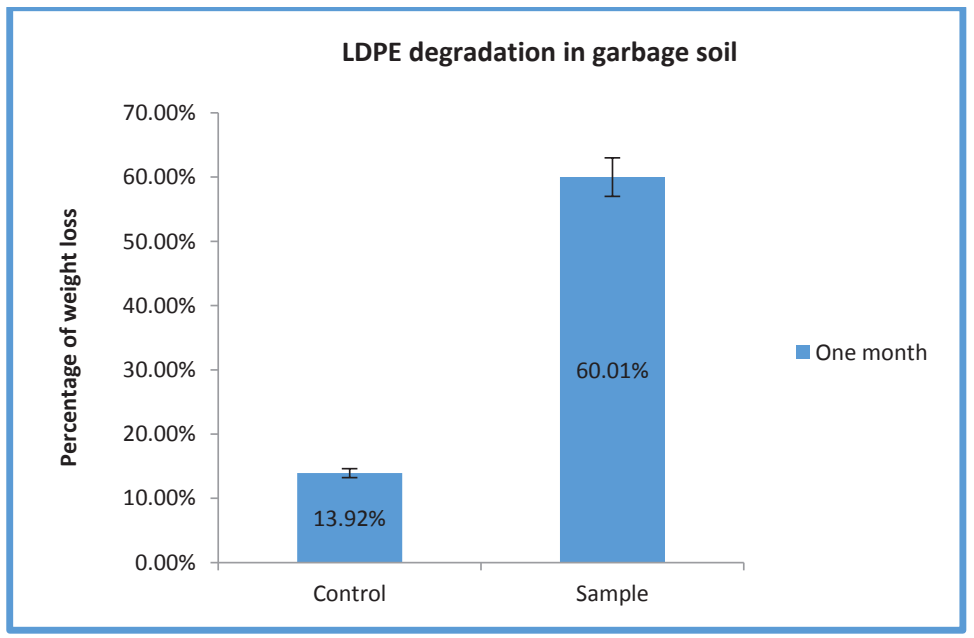

Fig. 6: Weight loss of LDPE in garbage soil.

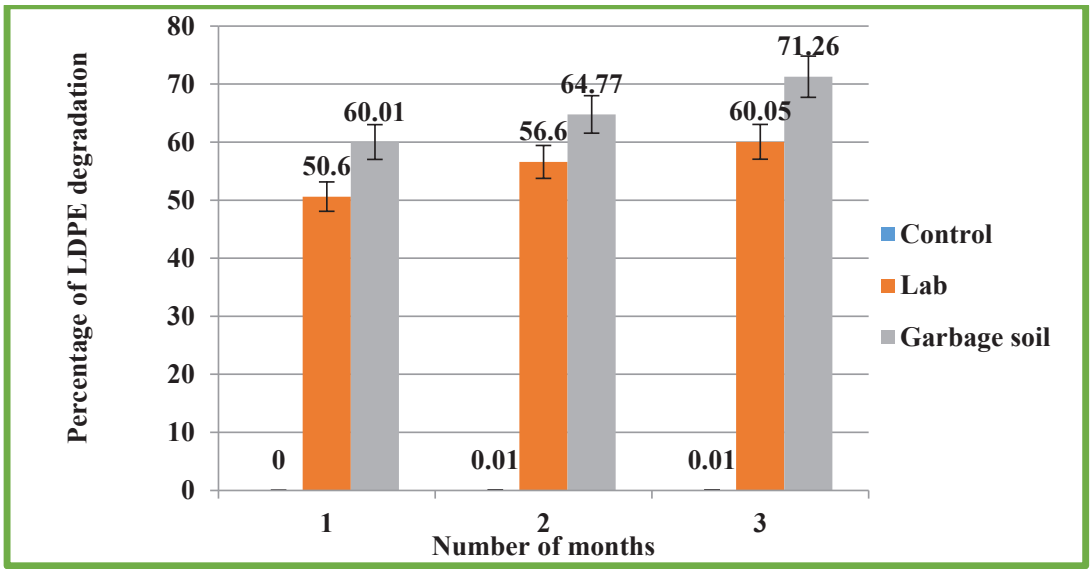

Fig. 7: Comparative studies between laboratory and field conditions through weight loss.

Control

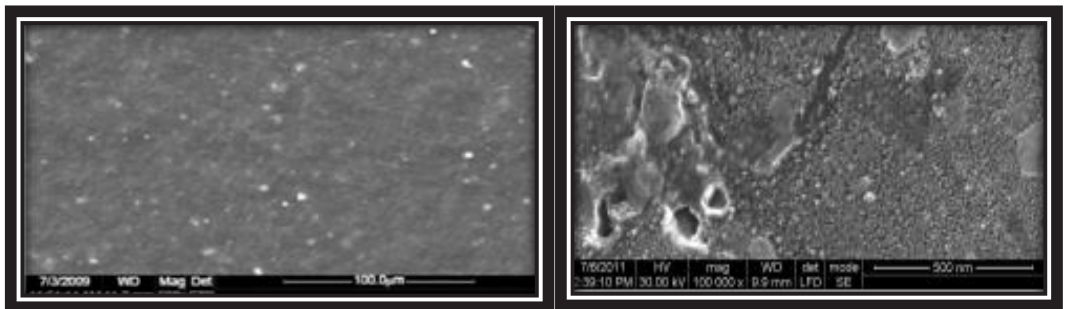

Fig. 8: SEM analysis of buried LDPE film. 
$2663.63 \mathrm{~cm}^{-1}, 1721.81 \mathrm{~cm}^{-1}, 1031.23 \mathrm{~cm}^{-1}$ and $912.92 \mathrm{~cm}^{-1}$. In the treated sample, new peaks were formed at 2663.63 $\mathrm{cm}^{-1}, 1722.63 \mathrm{~cm}^{-1}, 1081.28 \mathrm{~cm}^{-1,}$ and $966.12 \mathrm{~cm}^{-1}$. These peaks represent the formation of carbonyls and carboxylic acid in both control and sample by oxidizing the alkane and alkene bonds (Fig. $9 \& 10$ ). The changes in the control are due to microbes present in the garbage soil.

\section{DISCUSSION}

There are wide ranges of plastics that can be molded into desired shapes. For three decades' plastics have been extensively used as they are light in weight, strong and persistent for a long time without any damage (Kathiresan 2003). Low-density polyethylene was the first polyethylene derived through the polymerization of ethylene monomers. The hydrocarbon chain of low-density polyethylene is straight, crystalline, and tough to degrade after throwing away under normal environmental conditions. Disposal of low-density polyethylene is unmanageable in society and creates numerous deleterious effects polluting the environment and causing various health hazards. In the present research, the potent S.werraensis SDJM strain was isolated from LDPE dumped garbage sites, screened, and the effectiveness of biodegradation was assessed in both laboratory conditions and at garbage sites to control various anomalies created by LDPE pollution.

In the present research, LDPE degraded compounds were analyzed after 30 days of incubation by S.werraensis SDJM.

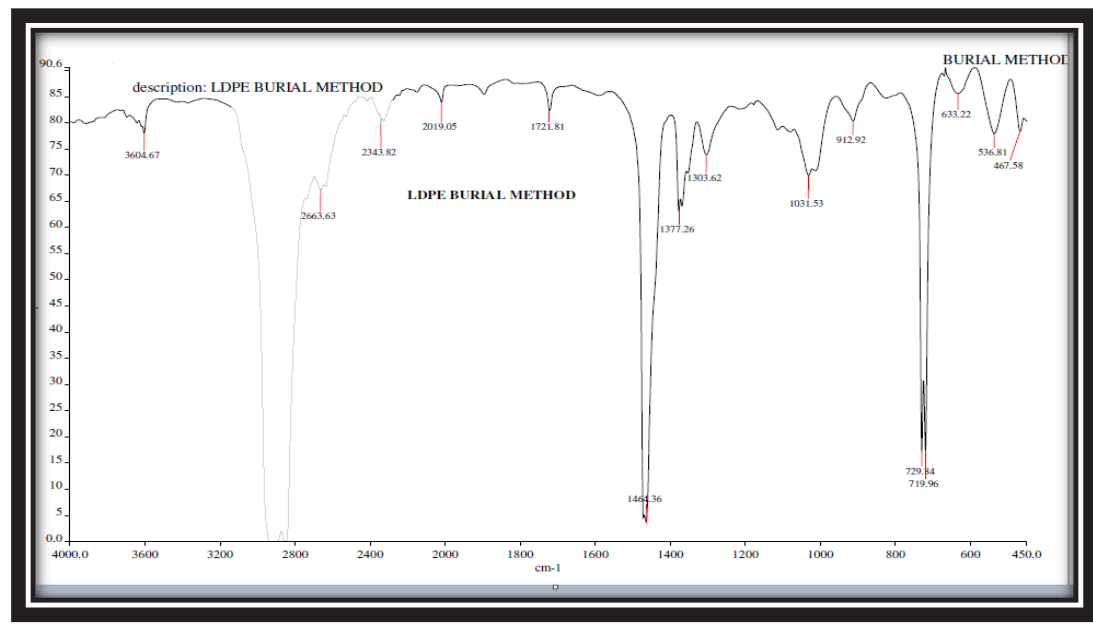

Fig. 9: FTIR spectrum of control without culture in garbage soil.

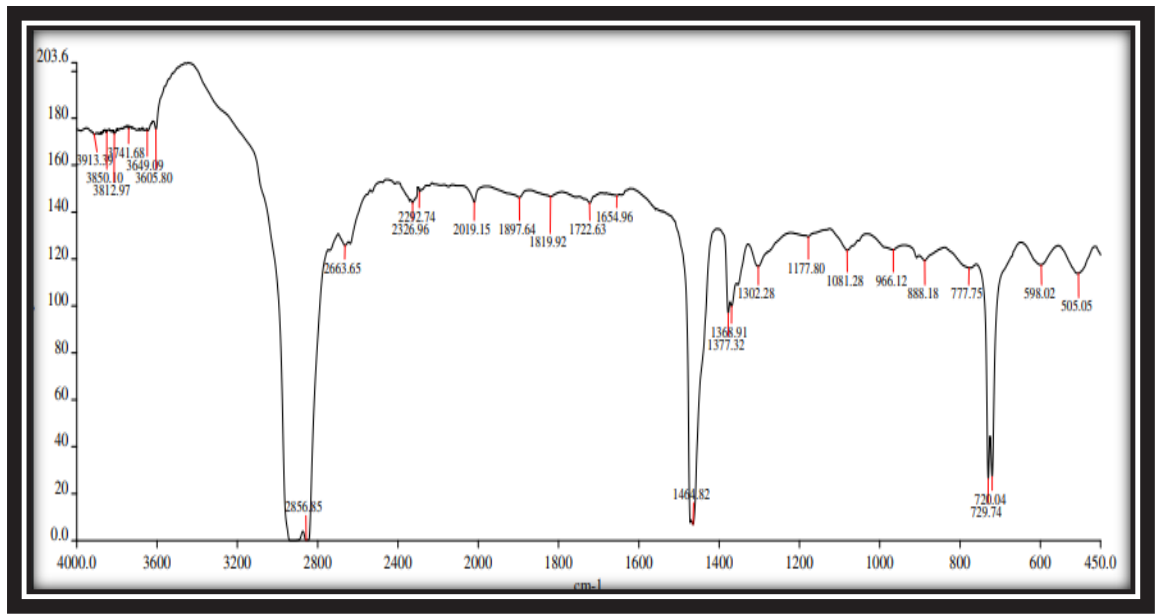

Fig. 10: FTIR spectrum with Streptomyces werraensis SDJMin garbage soil. 
Compounds like octane, decane, tetracosane, hexacosane, dotriacontene, tetratiacontene, tridecone, tetracontane, and pentacosane were detected in the treated sample through LCMS analysis whereas they were absent in control. Carbon dioxide released due to $\beta$-oxidation and TCA cycle was confirmed by GCMS using solid phase microextraction technique. These two sophisticated techniques prove that S.werraensis SDJM has the capacity to degrade LDPE in a short period of time.

The analysis data obtained was correlated with other researchers and found that GCMS analysis of LDPE treated with Acinetobacter baumannii revealed the formation of new peaks such as 2-butene, 2-methyl at 7.646 RT, acetone at 8.250 RT, and ethene at 17.288 RT. Acetone presence confirms A.baumannii degrade polymer and form carbonyl compound (Pramila \& Vijaya 2015). LDPE treated with Pseudomonas aeruginosa PAO1 for 120 days were analyzed through GCMS and identified alkanes, fatty acids (hexadecanoic acid, octanoic acid), hydrocarbons, oxygenated chemical compounds (aldehydes, ketones, esters, ether groups), and aromatic compounds formation (Bhone et al. 2012). The degraded products of LDPE were analyzed using HPLC and it was observed that the peak at 14.13 disappeared in treated samples of $40 \%$ and $50 \%$ of starch blend compared to the control sample. This confirms LDPE can be degraded by microorganisms (Veethahavyaa et al. 2016).

Microorganisms isolated from compost soil were tested for polyethylene degradation. Degraded products in the culture supernatant were collected, extracted using distilled ether, and analyzed by GCMS. The polyethylene degraded products were identified as octadecadienoic acid, octadecatrienoic acid, benzene dicarboxylic acid, and cyclopropanebutanoic acid (Mahalakshmi et al. 2012). Streptomyces species was isolated from East Azerbaijan, Iran soil, and the efficiency of HDPE degradation was tested through GCMS analysis. The degradation compounds were identified as tetradecanoic acid, eicosane, heneicosane, docosane, tricosane, tetracosane, hexacosane and benzoic acid (Ali et al. 2017). Aldehydes, ketones, and carboxylic acids were identified during the LDPE extrusion coating process. Biodegradation of polyethylene releases Ergosta-5, 22-dien-3-ol, acetate (3, 22 E), 1-monanalinoeoglycerol trimethylsilyl ether, betamethasone acetate, azafrin, 9, 12, 15-octadecatrienoic acid, 2, 3-bis [(trimetylsilyl) oxy] propyl ester, and (Z, Z, Z)-C27H52O4Si2) (Pranita 2010). The degraded products of low-density polyethylene by Achromobacter denitrificans was analyzed through GCMS and it was observed that octadecadienoic acid, octadecatrienoic acid, benzene dicarboxylic acid, and cyclopropanebutanoic acid were produced in 60 days of incubation (Ambikadevi et al. 2015).
Field trials were performed under natural garbage soil conditions and the obtained data was compared with laboratory trials. Garbage soil is a rich source of polyethylene degrading microorganisms as the soil is enriched with various waste materials along with plastic bags and the available nutrients in garbage endures them to grow for a long life by harboring the natural habitats. In the present study, LDPE was dumped in garbage soil with S.werraensis SDJM, and control without organism was kept in another location for comparative studies.

In one month, the weight loss of the sample is $60.01 \%$ and control is $13.92 \%$. SEM analysis and FTIR analysis were performed to identify the morphological and structural changes before and after degradation. It has been observed that degradation was more prominent in the sample compared to control. Finally, the results of weight loss in three months conducted in fields were compared with laboratory test results and found that $S$.werraensis SDJM could degrade LDPE by more than $10 \%$ by associating with soil microbes compared to laboratory conditions.

The above experimental data was compared with a field trial conducted to degrade the polymer and it was found that the soil burial method for degradation of polyethylene was determined by weight loss and SEM analysis. It has been noticed that the weight loss of composite sample (PE-g-starch) and true graft (PE) was about $88 \%$ and $84 \%$ respectively. Degradation of PE and PE-g starch was further confirmed by scanning electron microscopy (SEM analysis). This helps to identify the topographical changes of the polymer created by soil microorganisms due to degradation (Neena \& Inderjeet 2013).

Fourier transform infrared spectroscopy (FTIR) and SEM analysis were performed to identify the structural and surface changes of the degraded low-density polyethylene using bacterial consortium in enriched soil. The results obtained in the presence and absence of the consortium were compared with the untreated LDPE control sample. LDPE buried in soil exhibits $\mathrm{CH} / \mathrm{CH} 2$ stretching, bending, deformation and results in the formation of $\mathrm{C}-\mathrm{O}$ at $1,218.6 \mathrm{~cm}^{-1}$ and $1,031.6 \mathrm{~cm}^{-1}$. FTIR spectrum of LDPE treated with consortium reveals that there is the disappearance of $\mathrm{CH} 3$ bending and complete change was noticed between $1,300 \mathrm{~cm}^{-1}$ and $950 \mathrm{~cm}^{-1}$. A peak at $1628.4-1628.7 \mathrm{~cm}^{-1}$ was observed in both treated and untreated samples. SEM analysis was performed to LDPE control, untreated sample, and sample treated with consortia. In both the treated and untreated samples there is a noticeable change when compared with control. The reason behind the changes in the untreated sample is mainly due to natural habitants present in the soil (Shahbaz et al. 2013). 
Low-density polyethylene was subjected to environmental degradation by burying the sample in soil under natural conditions. To test the efficiency of degradation by soil microbes the samples were removed periodically from soil and tested using FTIR analysis. This helps us to identify structural changes of the polymer due to biodegradation and major absorption at $1400-1800 \mathrm{~cm}^{-1}$ indicating the presence of carbonyl peaks was found (Tabassum et al. 2010).

\section{REFERENCES}

Ali, F., Alireza, D., Najibeh, S. and Faezeh, N. 2017. Biodegradation of high density polyethylene using Streptomyces species. J. Coast. Life Med., 5(11): 474-479.

Ambikadevi, K., Lakshmi, B.K.M. and Hemalatha, K.P.J. 2015. Degradation of low-density polythene by Achromobacterdenitrificans strain S: A novel marine isolate. Int. J. Rec. Sci. Res., 6(7): 5454-5464.

Bhone, M.K., Ravi, C., Meena, K., Chu, S.L. and Kishore, S. 2012. Biodegradation of low-density polythene (LDPE) by pseudomonas species. Indian J. Microbiol., 52(3): 411-419.

Dennis, B.M. 2010. Book: Introduction to Industrial Polyethylene, Properties, Catalysts, and Processes. Wiley, New York, pp. 1-150.

Einas, I.A.M. and Hago, E.F.H. 2014. Effect of the low-density polyethylene carry bags waste on the asphalt mixture. Int. J. Eng. Res. Sci. Technol. 3(2): 86-93.

Environment Pollution Board 433. 2012. Health and Environmental Effects of Burning Waste Plastics. pp. 1-3.

Gajendiran, A., Krishnamoorthy, S. and Abraham, S. 2016. Microbial degradation of low-density polyethylene (LDPE) by Aspergillus clavatus strain JASK1 isolated from landfill soil. Biotech, 6(1): 52.

Ingavale, R.R. and Raut, P.D. 2018. Comparative biodegradation studies of LDPE and HDPE using Bacillus weihenstephanensis isolated from garbage soil. Nature Environment and Pollution Technology, 17(2): 649-655.

Kathiresan, K. 2003. Polyethylene and plastic degrading microbes from the mangrove soil. Revista de Biol. Trop., 51: 629-633.
Mahalakshmi, V., Abubakker, S. and Niren, A.S. 2012. Analysis of polyethylene degrading potentials of microorganisms isolated from compost soil. Int. J. Pharm. Biol. Arch., 3(5): 1190-1196.

Muthukumar, A. and Veerappapillai, S. 2015. Biodegradation of plastics: A brief review. Int. J. Pharm. Sci. Rev. Res., 31(2): 204-209.

Neena, G. and Inderjeet, K. 2013. Soil burial biodegradation studies of starch grafted polyethylene and identification of Rhizobium meliloti. J. Environ. Chem. Ecotoxicol., 5(6): 147-158.

Nupur, O., Neha, P., Surjit, S., Anil, B., Anamikashrivastava, P., Vivek, R. and Sutapa, B. 2017. Evaluation of hdpe and ldpe degradation by fungus, implemented by statistical optimization. Sci. Rep., 7: 1-10.

Okoh, E.B. and Atuanya, E.I. 2014. Impacts of soil composting and poultry manure on biodegradation of polyethylene. Int. J. Appl. Microbiol. Biotechnol. Res., 2: 18-29.

Piringer, O.G. and Baner, A.L. 2008. Plastic Packaging: Interactions with Food and Pharmaceuticals (2nd ed.). Wiley-VCH, Weinheim, Germany.

Pramila, R. and Vijaya Ramesh, K. 2015. Potential biodegradation of low-density polyethylene (LDPE) by Acinetobacterbaumanni. Afr. J. Biotechnol. Res., 7(3): 24-28.

Pranita, N.A. 2010. Studies on Biodegradation of Polythene, Thesis, Dr.Babasaheb Ambedkar Marathwada University, Aurangabad, pp.1-135.

Samuel, O. A., Sajid, S., Anicia, M. and Wayne, S. 2009. Chromatographic and spectral analysis of two main extractable compounds present in aqueous extracts of laminated aluminum foil used for protecting LDPEfilled drug vials. Int. J. Anal. Chem., 2009: 1-9.

Shahbaz, A., Mohd, N., Harshita, G., Haider, Z. and Sanjay, G. 2013. Biodeterioration studies of thermoplastics in nature using indigenous bacterial consortium. Environ. Sci., 56(3): 475-484.

Shalini, M. and Sasikumar, C. 2015. Effect of microbes on low-density polyethylene material degradation with reference to sem analysis. Int. J. Pharma Biosci., 6(4): 447-452.

Tabassum, M., Khan, M.R. and Mohd, A.H. 2010. Study of environmental biodegradation of LDPE films in soil using optical and scanning electron microscopy. Micron, 41(5): 430-438.

Veethahavyaa, K.S., Rajath, B.S., Sabike, N. and Manoj Kumar B. 2016. Biodegradation of low-density polyethylene in aqueous media. Procedia Environ. Sci., 35: 709-713. 